\title{
Custos sociais: Onde para o mercado?
}

Social Costs: Where Does the Market End?

Coûts sociaux : où s'arrête le marché?

\section{Vítor Neves}

\section{(2) OpenEdition}

\section{Journals}

Edição electrónica

URL: http://journals.openedition.org/rccs/4368

DOI: $10.4000 /$ rccs. 4368

ISSN: 2182-7435

\section{Editora}

Centro de Estudos Sociais da Universidade de Coimbra

\section{Edição impressa}

Data de publição: 1 dezembro 2011

Paginação: 55-68

ISSN: 0254-1106

\section{Refêrencia eletrónica}

Vítor Neves, "Custos sociais: Onde para o mercado? », Revista Crítica de Ciências Sociais [Online], 95 | 2011, posto online no dia 01 dezembro 2012, consultado o 14 novembro 2019. URL : http:// journals.openedition.org/rccs/4368; DOI : 10.4000/rccs.4368 


\section{VÍTOR NEVES}

\section{Custos sociais: Onde para o mercado?}

Os mercados constituem um poderoso mecanismo de coordenação económica. Ainda assim, as suas limitações não podem nem devem ser ignoradas. Os custos da mais diversa ordem com origem na atividade das empresas no quadro do capitalismo e externalizados, isto é, transferidos para outros agentes ou para a sociedade como um todo sem repercussão no mecanismo de preços, são um exemplo particularmente relevante dessas limitações. Neste artigo põem-se em confronto as diferentes conceções sobre os custos sociais existentes na literatura económica, desde a identificação do problema como uma "falha do mercado" até à conceção mais heterodoxa (e também menos conhecida) de K. William Kapp, segundo a qual os custos sociais são um problema intrínseco e inevitável no contexto institucional do capitalismo. Num primeiro momento discute-se a natureza do problema. Em seguida, apresentam-se, se bem que de forma muito sumária, duas linhas fundamentais de fratura entre a abordagem convencional dominante e a abordagem heterodoxa de Kapp: o conceito de eficiência adotado e o modo como é vista a questão da valoração dos custos sociais.

Palavras-chave: análise custo-eficiência; custos sociais; externalidades; falhas de mercado; mercado; valor social.

\section{Introdução}

Num estimulante livro publicado recentemente, The Value of Nothing, o autor, Raj Patel, ilustra de forma muito clara, através de exemplos vários, a diversidade, amplitude e, sobretudo, a importância dos custos sociais decorrentes da atividade económica empresarial no quadro do capitalismo contemporâneo (Patel, 2011, em particular o capítulo 3). A verdade, porém, é que o nosso conhecimento acerca destes custos e sobre o modo de lidar com eles ao nível das políticas públicas está ainda longe de poder ser considerado consolidado.

A teoria económica convencional dos custos sociais, com origem no trabalho de A. C. Pigou, The Economics of Welfare (Pigou, 1932 [1920]), mas sem a subtileza da análise deste autor, assenta no entendimento de que 
tais custos são "externalidades" - uma falha do mercado. Esta abordagem, relativamente incontroversa até ao início dos anos 1960, foi fortemente abalada pelo trabalho de Ronald Coase, The Problem of Social Cost (1960). Para este autor, em vez de uma falha do mercado, o problema dos custos sociais é, na verdade, o resultado da inexistência de mercados, seja porque os direitos de propriedade que os viabilizariam não são claramente definidos, seja porque os custos de transação (custos de funcionamento do mercado) são proibitivos. Em ambas as abordagens, porém, os custos sociais são reduzidos a um mero problema de alocação ineficiente dos recursos económicos. E embora represente uma significativa mudança de paradigma na análise dos custos sociais (Medema, 1994), a análise empreendida por Coase pode, ainda assim, ser considerada canónica utilizando, no fundamental, o quadro concetual e os instrumentos analíticos da teoria microeconómica tradicional. Não é, por isso, de estranhar que faça hoje parte de quase todos os manuais de Microeconomia e de Economia Pública estudados nas universidades por esse mundo fora.

À margem deste pensamento dominante merece destaque o trabalho de Karl William Kapp, um destacado, mas relativamente pouco conhecido, economista institucionalista crítico na tradição do institucionalismo americano com fortes raízes no pensamento europeu. Kapp dedicou ao problema dos custos sociais grande parte do seu labor científico ao longo de mais de um quarto de século. Num livro seminal, The Social Costs of Private Enterprise, ${ }^{1}$ e em vários trabalhos posteriores, Kapp mostra que os custos sociais são um produto inexorável da lógica intrínseca de funcionamento do capitalismo, com uma dimensão política incontornável, e põe em causa a busca de soluções para o problema dos custos sociais pela via do mercado (como tende a defender Coase) ou com base no cálculo económico assente nos preços de mercado (como acontece também no caso de Pigou).

Importa, assim, pôr em confronto estas diferentes conceções sobre os custos sociais. Desde logo, procurando clarificar a natureza do problema. Será esse o objeto da próxima secção. Dado o relativo desconhecimento da obra de K. William Kapp, uma atenção particular será conferida ao trabalho deste autor. Na secção seguinte procurarei apresentar, se bem que de forma muito sintética, duas linhas fundamentais de fratura entre a abordagem convencional dominante sobre os custos sociais e a abordagem heterodoxa de K. William Kapp: (1) o conceito de eficiência relevante e (2) o problema da valoração dos custos sociais. Algumas notas finais concluem o texto.

\footnotetext{
${ }^{1}$ Publicado em 1950, este livro seria reeditado em 1963 com o título The Social Costs of Business Enterprise.
} 


\section{A natureza do problema}

\section{Os custos sociais como "externalidades" (falha do mercado)}

$\mathrm{Na}$ literatura económica convencional os custos sociais são externalidades. ${ }^{2}$ Estas são entendidas como consequências não planeadas da atividade de um ou mais agentes económicos (indivíduos ou empresas) ${ }^{3}$ sobre o bem-estar ou a capacidade produtiva de outro ou outros intervenientes no processo económico, relativamente às quais não é possível obter ou exigir compensação. ${ }^{4}$ São efeitos residuais ou secundários ${ }^{5}$ da atividade económica principal do agente - efeitos "externos" - que escapam à ação do mecanismo de preços. São economias ou deseconomias externas.

O problema fundamental aqui identificado é a incapacidade do mecanismo de preços induzir uma compensação pelos danos (ou benefícios) causados, ou, na linguagem dos economistas, levar à internalização desses efeitos. ${ }^{6}$ Trata-se de uma falha do mercado, ou seja, uma situação em que os mercados se revelam incapazes de garantir a afetação "eficiente" dos recursos económicos. No quadro analítico da economia dominante isto é o mesmo que dizer que o ótimo de Pareto é violado. ${ }^{7}$ E não sendo possível uma compensação, na lógica do teste da melhoria potencial de Pareto, isto é, nas situações em que os danos causados pela ação de um agente são maiores do que as vantagens que trazem para um qualquer outro agente ou setor da economia, a concretização daquele "ótimo" é impossível. ${ }^{8}$ As externalidades constituem-se então como um problema, havendo justificação para uma ação corretiva. ${ }^{9} \mathrm{Na}$ tradição pigouviana isto significa, em geral, ação do Estado por via de impostos, subsídios ou regulamentação pública.

\footnotetext{
${ }^{2}$ Externalidades negativas. Podemos, paralelamente, falar de externalidades positivas quando, em vez de custos, estão em causa benefícios sociais.

${ }^{3}$ A origem específica da externalidade - produção ou consumo - é irrelevante.

${ }^{4}$ Os danos não percecionados como tal pelos diversos atores económicos não são considerados externalidades. A degradação ambiental, por exemplo, só se constitui como um problema relevante na medida em que alguém sinta que o seu bem-estar é afetado (Franzini, 2006: 58).

${ }^{5}$ Veja-se, por exemplo, Fernandes (2011: 140).

${ }^{6}$ Os efeitos sobre terceiros internalizados por ação do mecanismo de preços - as chamadas externalidades pecuniárias - são, deste ponto de vista, irrelevantes. Não são sequer consideradas como verdadeiras externalidades. Decorrem do normal funcionamento do mercado. É o caso, por exemplo, dos efeitos negativos sobre o bem-estar da população residente numa área turística decorrentes dos aumentos de preços na época balnear devido ao grande afluxo de turistas.

7 Designa-se por ótimo de Pareto (ou eficiência de Pareto) uma situação em que não é possível melhorar o nível de bem-estar de um qualquer agente económico sem que isso implique a diminuição do bem-estar de pelo menos um outro agente económico.

${ }^{8}$ Sobre o teste de melhoria potencial de Pareto, ou critério de compensação de Kaldor-Hicks, veja-se, por exemplo, Bromley (1990) ou Zerbe Jr. (2001).

9 Apenas as externalidades relevantes do ponto de vista do ótimo de Pareto interessam. Se, por exemplo, as decisões de uma empresa afetarem negativamente o bem-estar dos seus trabalhadores
} 


\section{Os custos sociais como resultado da inexistência de mercados}

Ronald Coase rejeita a ideia dos custos sociais como danos externos (recusando também, por isso, o termo "externalidades"). Para este autor, é inadequado pensar o problema dos custos sociais como o resultado da imposição unilateral de um dano a outrem, como uma questão de falta de compensação (internalização) por parte do agente gerador do dano ao(s) agente(s) que suporta $(m)$ esse dano. Todos são, em última instância, responsáveis pela existência e resolução do problema.

Os custos sociais decorrem de situações em que os agentes envolvidos estabelecem entre si, no que respeita ao objeto do dano, uma relação de reciprocidade. Na relação entre dois agentes, $\mathrm{A}$ e B, "ambas as partes causam o dano". Evitar o dano a B implica causar um dano a A. Os custos existem para ambas as partes. Por isso é desejável que ambas levem em consideração o dano ao decidir como agir (Coase, 1960: 13).

A questão que se deve colocar, como Coase se esforçou por mostrar recorrendo a vários exemplos reais de processos judiciais, será: deve A ser autorizado a causar um dano a B ou deve B ser autorizado a causar um dano a $A$ ? Trata-se, pois, de decidir que interesses vão ser protegidos pela lei e pelos tribunais, isto é, que interesses vão adquirir o estatuto de direitos (Medema, 1994: 69). Estes têm uma natureza dual (Medema, 1994: 68-69; 2009: 105). A atribuição de um direito a uma parte implica expor outros aos efeitos do exercício desse direito, o que implica custos. ${ }^{10}$

Mais do que uma falha do mercado, os custos sociais evidenciam, para Coase, um problema de inexistência de mercados derivado da indefinição dos direitos de propriedade que tornem possível (e facilitem) as transações. É afinal uma falha do Estado (Medema, 1996: 102). A partir do momento em que tais direitos sejam definidos com clareza, a sua transação (voluntária) a favor de quem mais os valoriza poderá ocorrer, conduzindo, na ausência de custos de transação, ${ }^{11}$ a uma alocação eficiente de Pareto, independentemente da atribuição inicial dos direitos de propriedade. O problema deixará de existir. É o famoso resultado conhecido como "teorema de Coase".

Na realidade, porém, dada a relevância empírica incontornável dos custos de transação - impedindo a concretização prática do teorema -, aquilo que segundo Coase é realmente importante não é este resultado, tão enfatizado

ou da comunidade mas permitirem aumentar o bem-estar dos seus acionistas mais do que o dano por elas causado, não haverá justificação, numa lógica de eficiência (a única relevante no quadro desta abordagem), para quaisquer ações corretivas.

10 "O custo de exercer um direito é sempre a perda que se sofre algures em consequência do exercício desse direito - a incapacidade de atravessar uma terra, estacionar um carro, construir uma casa, desfrutar uma vista, ter paz e sossego ou respirar ar limpo" (Coase, 1960: 44).

${ }^{11}$ Custos de funcionamento do mercado. 
pelos entusiastas do mercado como solução (e por grande parte dos manuais de Economia), mas precisamente o papel fundamental do direito (e dos tribunais) na afetação dos recursos económicos. Devido aos custos proibitivos da negociação, os direitos tendem a ser exercidos nos termos da sua atribuição inicial - "rights stick where they hit" (Medema, 1994: 76).

A resposta à questão de saber a quem devem ser atribuídos os direitos de propriedade é, segundo Coase, clara: deve evitar-se o dano mais grave (Coase, 1960: 2). Ao invés de colocar todo o ónus no "responsável" pelo dano e tentar por todos os meios eliminar esse dano, a solução para o problema dos custos sociais residirá na escolha da alternativa mais vantajosa. É um exercício de cálculo de ganhos e perdas. Trata-se de saber se o ganho resultante de impedir o dano é maior ou menor do que a perda provocada pela ação visando a sua eliminação (Coase, 1960: 27). Por exemplo, se a poluição dos rios provoca a morte de peixes, deve comparar-se o valor do peixe perdido com o valor da produção tornada possível pela atividade poluidora. A regra de decisão, defende Coase, é escolher a situação que maximiza o valor total da produção.

Isto implica, naturalmente, saber o valor do que é obtido e o valor daquilo que é sacrificado. Segundo Coase (1970a: 35), "nem sempre, ou nunca, é fácil decidir qual o curso [da ação] a tomar." Mas, em seu entender "a natureza da escolha é clara." Trata-se, continuando a usar as suas palavras, de uma decisão que "não é diferente da decisão sobre se um campo deve ser usado para cultivar trigo ou cevada, e não é certamente uma decisão acerca da qual devamos manifestar grande emoção. É uma questão importante e difícil, mas é certamente apenas uma questão de valoração" (Coase, 1970b: 9, itálico acrescentado).

Em resumo, ao mesmo tempo que redefine a natureza do problema, Coase põe assim em causa a abordagem tradicional das externalidades em dois aspetos fundamentais: 1) a ideia de que os custos sociais correspondem a uma "falha do mercado"; e 2) o entendimento de que a resolução do problema passa inevitavelmente por ações "corretivas" do Estado, designadamente impostos e subsídios. Mas, como ficará mais claro mais à frente, o raciocínio é, ainda assim, o da teoria microeconómica tradicional.

\section{Os custos sociais como um problema intrínseco ao capitalismo}

A análise dos custos sociais de $\mathrm{K}$. William Kapp rompe em vários aspetos fundamentais com as abordagens anteriores. Para este autor os custos sociais são custos "não pagos" pelos agentes que os produzem, ${ }^{12}$ fenómenos generalizados nas economias capitalistas, se bem que muito

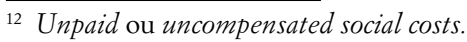


heterogéneos, intrinsecamente ligados à atividade produtiva e inevitáveis no quadro das economias baseadas no lucro. São, em todo o caso, custos que poderão ser minimizados através de reformas e mudanças institucionais apropriadas.

Segundo Kapp, a existência de custos sociais deve-se fundamentalmente à circunstância de a busca do lucro resultar num prémio à minimização dos custos privados de produção. Ao minimizarem os seus custos internos, as empresas tenderão a transferir para terceiros e para a comunidade em geral e efetivamente a maximizarem os custos sociais (isto é, a parte dos custos totais a que na literatura económica tradicional se convencionou chamar custos "externos").

Em vez de meros efeitos residuais ou secundários de uma atividade principal, um coproduto indesejável, os custos sociais serão antes uma caraterística intrínseca e necessária ao funcionamento das economias baseadas no lucro. A economia capitalista é, nas palavras de Kapp, uma "economia de custos não pagos".

Estes custos cobrem um amplo espectro de deseconomias ambientais e sociais, incluindo aspetos tão diversos e heterogéneos como a poluição ambiental; o esgotamento dos recursos não renováveis e a exaustão dos recursos renováveis; o congestionamento urbano; a deterioração das condições de trabalho, acidentes de trabalho e doenças profissionais; os efeitos nocivos das mudanças tecnológicas, a instabilidade económica e o desemprego; ou, como tem vindo a acontecer com particular pungência no decurso da presente crise, o sacrifício do bem-estar das pessoas ditado pelos ritmos, interesses e exigências da engrenagem económica. Incluem, na verdade, toda "uma variedade de 'deseconomias', riscos acrescidos e incertezas que podem estender-se até muito longe no futuro" (Kapp, 1963: 185).

Numa releitura recente da obra de Kapp, Maurizio Franzini (2006) defende que os custos sociais kappianos devem ser entendidos como violações de direitos sociais básicos. Serão mesmo, nas suas palavras, o reverso desses direitos. Assim, será totalmente irrelevante se os danos causados pela ação de um agente, medidos pelas perdas de bem-estar por parte de quem os sofre, são maiores ou menores do que as vantagens que daí resultam para quem os produz (uma questão central, como vimos, no quadro da análise convencional das externalidades). Os custos sociais, como sublinha este autor, são violações de direitos sociais, perpetradas pelo capitalismo de mercado, ocorram essas violações numa situação de eficiência de Pareto ou não. Os danos sociais, mesmo que inferiores aos ganhos das empresas, não deixarão de constituir uma violação de direitos sociais e não são, por esse facto, menos importantes. 
O livre funcionamento do mercado promove, segundo Kapp, a "externalização" ou, como ele preferia dizer, a transferência em grande escala de uma parte significativa dos custos totais da produção para a comunidade (a conversão dos custos "externos" em custos sociais).

As possibilidades de "resistência" a esta transferência de custos pela via da negociação de interesses conflituantes - numa linha de pensamento à Coase - são, na ótica de Kapp, limitadas. Várias razões podem ser apontadas nesse sentido. Kapp sugere as seguintes:

(i) Alguns custos sociais, como os danos causados à saúde humana, podem permanecer ocultos (e ignorados pelas pessoas afetadas) durante um largo período de tempo; (ii) No caso de situações catastróficas como cheias, deslizamentos de terras e outros desastres "naturais", causadas, ou pelo menos agravadas, pela utilização irracional dos recursos, os custos sociais, com todo o sofrimento humano envolvido, podem ser percecionados como o resultado de causas meramente naturais;

(iii) Alguns danos, sendo elevados como um todo, estão disseminados por um grande número de pessoas de tal forma que as perdas individuais são relativamente negligenciáveis e por isso não parecem justificar uma ação decidida de resistência; (iv) As pessoas diretamente afetadas pelos custos sociais podem não ter meios (financeiros, legais ou outros) para agir de forma apropriada, nomeadamente pelo recurso à via judicial, no sentido de impedir que os danos que lhes estão a ser infligidos persistam;

(v) Em geral, as pessoas afetadas estão numa posição de inferioridade negocial tendo uma reduzida capacidade para resistir ao poder das empresas e suas organizações; para estas últimas a atividade de lobbying visando entravar medidas de regulação dos seus negócios é frequentemente mais rentável do que tomar medidas no sentido da prevenção dos custos sociais;

(vi) Finalmente - e esta é porventura a questão fundamental - os custos sociais são, em regra, um produto inexorável da lógica de funcionamento da economia de mercado como um todo. (1978 [1963]: 267-268)

$\mathrm{Na}$ verdade, Kapp contesta a ideia de que os custos sociais possam, em geral, ser razoavelmente concebidos num quadro de relações bilaterais e com uma natureza recíproca. Para ele, os custos sociais estão associados a relações não-mercantis assimétricas, frequentemente involuntárias, moldadas por entidades mais ou menos dominantes que impõem os seus interesses aos setores económica e politicamente mais débeis da sociedade. Os atores económicos têm diferentes possibilidades de acesso à informação relevante e diferente capacidade para controlar ou mesmo manipular essa informação, assim como um desigual poder de negociação. Há assim uma dimensão de 
poder, e portanto política, no problema dos custos sociais - ignorada pela teoria dominante - sem a qual o problema dos custos sociais não poderá ser plenamente compreendido.

Vale a pena aqui citar o próprio Kapp:

[O] facto de uma parte dos custos de produção poder ser transferida para terceiros ou para a sociedade como um todo é apenas uma outra maneira de dizer que os custos e, consequentemente, os lucros dependem, pelo menos em certa medida, do poder da empresa para o fazer. Em suma, o que a teoria convencional trata como um dado é, na verdade, já o resultado de uma constelação de interdependências mercantis e não mercantis entre unidades de caráter heterogéneo e com diferentes graus de controlo e dominação económica. (Kapp, 1969: 335, itálico acrescentado)

Alguns anos mais tarde, num dos seus últimos trabalhos, Kapp acrescentaria:

[O] processo causal [responsável pela disrupção ambiental] não é, em regra, de caráter bilateral, com poluidores específicos causando danos a indivíduos específicos (ou outras partes afetadas) identificáveis. Na verdade, o processo nada tem em comum com uma típica relação mercantil entre duas pessoas; não éo resultado de uma qualquer transação contratual voluntária. As pessoas afetadas estão, regra geral, desprotegidas; não têm voz na matéria; são vítimas de um processo relativamente ao qual têm pouco ou nenbum controlo. A degradação da qualidade do meio ambiente acontece, por assim dizer, nas suas costas, e as suas possibilidades de recurso são limitadas ou ineficazes no quadro das leis de compensação em vigor. (Kapp, 1977: 531, itálico acrescentado)

Tudo isto nos leva a uma característica central da abordagem de Kapp: a ideia de que os processos causais que ligam a produção, o ambiente natural e social e os indivíduos envolvem dimensões "económicas" e "não-económicas" numa complexa rede de interdependências sistémicas.

Os custos sociais são, em seu entender, o resultado da ação combinada de uma pluralidade de fatores, relações e processos causais, só podendo ser plenamente compreendidos (e os seus efeitos minimizados) no quadro de uma abordagem que reconheça: (1) o caráter aberto dos sistemas socioeconómicos e (2) a natureza circular e cumulativa daqueles processos causais (Kapp, 1976). Esta natureza cumulativa impõe a consideração de limiares críticos (ou zonas críticas), ausente da análise convencional, a partir dos quais os custos sociais ganham nova relevância e significado. Mecanismos lineares de causa e efeito e abordagens teóricas com base na noção convencional de equilíbrio serão inadequados para analisar os custos sociais. 


\section{Linhas de fratura}

São muitas as diferenças - umas mais significativas do que outras - entre as várias abordagens sobre os custos sociais. Salientarei duas que, em meu entender, constituem linhas de fratura fundamentais entre a abordagem convencional dominante e a abordagem radicalmente heterodoxa de Kapp. A primeira tem a ver com o conceito de eficiência subjacente às duas abordagens. A segunda diz respeito ao problema da valoração. Em ambas se percebe a centralidade que o mercado ocupa no pensamento dos autores que temos vindo a analisar. ${ }^{13}$

A questão dos custos sociais é, na verdade, do princípio ao fim, uma discussão sobre o lugar do mercado. Daniel Bromley sintetiza bem a posição dominante entre os economistas sobre o papel do mercado:

A centralidade dos mercados é tão pronunciada na Economia que os casos em que os mercados não funcionam (ou não podem funcionar) são considerados como falhas de mercado - com a implicação imediata de que devemos ver o que é necessário para que os mercados sejam estabelecidos. Ou procuramos obter o resultado que se verificaria se um mercado não pudesse deixar de ser estabelecido. (Bromley, 1997: 1389)

Bem diferente é a posição de Kapp. Para este importa sobretudo pensar os limites do mercado. Uma coisa é certa. Discutir o problema dos custos sociais é, inevitavelmente, discutir o papel do mercado (na teoria e na realidade das nossas economias). A questão é complexa e não cabe neste texto, evidentemente, uma discussão detalhada de todos os aspetos envolvidos. No que se segue procurarei tão-somente dar conta dos termos do debate.

\section{Eficiência de Pareto versus eficiência social}

A análise tradicional dos custos sociais, tal como a de Coase, apesar de todas as diferenças, têm um ponto fundamental em comum - conceberem os custos sociais como um problema de eficiência económica (um afastamento relativamente ao ótimo de Pareto). Mesmo quando se admite, como faz Coase, que a perspetiva da eficiência não esgota a questão dos critérios de escolha e que "os problemas da economia do bem-estar devem, em última análise, dissolver-se num estudo da estética e da moral" (Coase, 1960:43), tudo se resume, na perspetiva do economista, a decidir, tendo em vista evitar

${ }_{13}$ A dimensão do Poder e assimetria dos agentes, presente no trabalho de Kapp, por contraposição à ideia de transações voluntárias entre partes iguais num quadro de reciprocidade, defendida por Coase, constituirá também, como sugeri noutro lugar (Neves, 2012), uma linha de fratura entre as duas abordagens. 
o dano mais grave, se o ganho derivado de prevenir o dano é maior ou menor do que a perda decorrente da ação que visa a sua eliminação. As questões de eficiência e da equidade são mantidas em dois planos totalmente separados. Ao economista qua economista apenas interessa a eficiência - os ganhos agregados ao nível da produção de bens (mercadorias). ${ }^{14}$ As questões relativas à repartição do rendimento e ao bem-estar social são do domínio ético, relativamente ao qual o economista não tem qualquer tipo de expertise.

Kapp rejeita uma tal conceção por a considerar estritamente formal, estática, parcial e incompleta. Vai mesmo ao ponto de a classificar como "vazia" e "ambígua" (Kapp, 1965: 305-306). Em seu entender, ela não fornece critérios minimamente adequados para a avaliação do grau de sucesso ou fracasso na solução do problema da eficiência social. Isto porque não toma (nem pode tomar) em consideração o contexto institucional, a relevância das variáveis tempo (histórico) e espaço (social), as possibilidades de mudança institucional, ou as reais necessidades e requisitos básicos da vida humana. E porque, além disso, assume, erroneamente, uma falsa dicotomia entre fins "económicos" e "não económicos".

Toda a análise dos custos sociais de Kapp assenta, na verdade, na ideia de que o que importa é maximizar os benefícios da atividade económica - entendidos enquanto valores sociais - com um mínimo de custos sociais. Trata-se de um problema de eficiencia social. Para Kapp, como para J. M. Clark antes dele, falar de eficiência social significa pensar o desempenho global da economia do ponto de vista dos valores da sociedade, o que implica definir critérios substantivos (e não meramente formais) e indicadores objetivos de bem-estar, assentes numa teoria substantiva das necessidades humanas essenciais e do comportamento humano.

Ainda assim, considera Kapp, tais indicadores não dispensam uma forte componente de deliberação coletiva e decisão política acerca dos valores e objetivos sociais a prosseguir. Os custos sociais são, acima de tudo, um problema de organização institucional da economia. Constituem um problema coletivo cuja resolução exige respostas coletivas.

\footnotetext{
${ }^{14}$ Com Pigou as preocupações com a eficiência e a equidade estavam ainda ambas presentes. Contudo, a questão da impossibilidade de comparação interpessoal das utilidades, suscitada por Robbins (1932), viria a traduzir-se, com o desenvolvimento do critério de Kaldor-Hicks da melhoria potencial de Pareto no final dos anos 1930, na separação estrita destes dois critérios normativos (ver Zerbe Jr., 2001). Progressivamente a profissão vai interiorizando a ideia (errada) de que a eficiência, ao contrário da equidade, pode ser pensada como isenta de valores. Como refere Bromley (1990: 93), "uma vez que a eficiência deriva da produção, que se considera que uma maior produção de bens e serviços não implica qualquer juízo de valor, e uma vez que a produção pode ser avaliada pelos preços de mercado - os quais por sua vez são considerados neutros - a eficiência tornou-se sinónimo de análise objetiva."
} 


\section{A questão da valoração}

No quadro da abordagem convencional o problema dos custos sociais é, no fim de contas, como vimos, redutível a um problema de valoração. Coase foi a esse respeito de uma clareza cristalina. Trata-se de determinar o valor dos custos e benefícios com base na informação dada pelos preços de mercado e escolher a solução que maximiza os benefícios líquidos.

São sabidas as dificuldades práticas deste empreendimento, designadamente no que respeita à atribuição de valor aos bens não mercantis. Como o são as objeções filosóficas à monetarização geral da vida humana e a consciência de que, pelo menos para algumas coisas, a atribuição de um valor monetário é no mínimo questionável. Mas para a maioria dos economistas trata-se tão-somente da utilização, necessária e inevitável, de um conveniente padrão de medida ("the measuring rod of money"), sem o qual a escolha racional é considerada impossível. Nas palavras de Pearce (1978: 3), "goste-se ou não, qualquer decisão implica uma valoração monetária".

Para Coase os preços de mercado e, mais genericamente, a possibilidade de usar o padrão monetário, estão no âmago da análise económica. É essa possibilidade, aliás, que, em seu entender, lhe dá a vantagem, quando comparada com as outras ciências, para analisar o funcionamento do sistema económico (Coase, 1994 [1977]).

Para Kapp, porém, os custos sociais, tal como os benefícios sociais, têm de ser considerados como fenómenos extra-mercado (Kapp, 1970). Critérios monetários como o princípio da disposição para pagar ou para aceitar uma compensação com base nos preços de mercado são inadequados para a avaliação dos custos sociais e consequente deliberação quanto ao curso de ação a seguir. Os preços gerados pelo mercado, na medida em que não refletem adequadamente a importância relativa das necessidades humanas, a escassez relativa dos fatores de produção e os reais custos totais de produção, são indicadores "não somente imperfeitos e incompletos, mas enganadores” (Kapp, 1970: 843-844).

É forçoso, pois, segundo Kapp, proceder à avaliação dos custos e benefícios em termos do valor que traduzem para a sociedade ("value to society"). ${ }^{15}$ Preço de mercado e valor social estão longe de ser uma e a mesma coisa. Construir uma teoria do valor social constitui, para este autor, o problema central da teoria económica (Kapp, 1978 [1963]: 293). Tal exige, defende Kapp, a definição de critérios objetivos acerca do que é necessário e essencial à vida e à sobrevivência humanas - o seu referencial fundamental - e uma nova contabilidade social.

15 "Value to society" e não "value in society", na feliz expressão de J. M. Clark (2009 [1936]: 61), a quem Kapp foi buscar o conceito. 


\section{Notas finais}

Os mercados - e os preços que eles geram - constituem um poderoso mecanismo de coordenação económica. Mas, como terá ficado claro neste texto, as suas limitações são consideráveis. Os custos da mais diversa ordem "externalizados" pelas empresas no quadro do capitalismo contemporâneo, sem qualquer repercussão no mecanismo de preços e nas decisões de alocação de recursos, são um exemplo particularmente relevante dessas limitações.

Para a maioria dos economistas trata-se, sem dúvida, de um problema económico relevante - o problema das externalidades, como é em geral designado na literatura económica convencional - a exigir uma resposta ao nível da definição das políticas públicas. As soluções apontadas são diversas. Em alguns casos privilegia-se a ação pública, como acontece com os chamados impostos pigouvianos ou de regulamentação da atividade económica privada; noutros, soluções assentes na definição de direitos de propriedade e na criação de mercados, como é o caso bem conhecido dos mercados de licenças de emissão de $\mathrm{CO}_{2}$. Contudo, para estes economistas, as "externalidades" não põem em causa os fundamentos teóricos básicos da análise económica tradicional, designadamente o cálculo económico baseado nos preços de mercado ou a análise da eficiência assente no ótimo de Pareto.

Muito diferente, como vimos, é a abordagem dos custos sociais desenvolvida por K. William Kapp. Para este autor, além de constituírem um problema económico fundamental e incontornável nas economias capitalistas, os custos sociais constituem um enorme desafio à ciência económica contemporânea. Se os custos sociais têm a sua origem no quadro da economia de mercado capitalista, a solução para este problema terá de transcender a lógica do mercado.

Como escrevem os organizadores de Social Costs and Public Action in Modern Capitalism, uma imprescindível coletânea de textos inspirados na obra de Kapp:

Ao concentrar-se no mercado como a única economia possível, a teoria formal implicitamente favorece aqueles interesses económicos e sociais que mais têm a ganhar com um mercado [socialmente] desincrustado. [...] Os objetivos sociais devem ser uma prioridade para a economia, e a economia deve ser o meio para os realizar, em vez de uma restrição. O desempenho da economia deve ser avaliado em termos dos objetivos sociais que ela pode realmente alcançar. (Elsner et al., 2006: 8)

É um exercício complexo e difícil, mas que indubitavelmente vale a pena empreender. 


\section{Referências bibliográficas}

Bromley, Daniel (1990), “The Ideology of Efficiency: Searching for a Theory of Policy Analysis”, Journal of Environmental Economics and Management, 19, 86-107.

Bromley, Daniel (1997), "Rethinking Markets", American Journal of Agricultural Economics, 79(5), 1383-1393.

Clark, John M. (2009), Preface to Social Economics: Economic Theory and Social Problems, in Moses Abramovitz; Eli Ginzberg (orgs.). New Brunswick: Transaction Publishers [ed. orig.: 1936].

Coase, Ronald (1960), "The Problem of Social Cost", The Journal of Law E Economics, 3 (October), 1-44.

Coase, Ronald (1970a), "Social Cost and Public Policy", in George Edwards (org.), Exploring the Frontiers of Administration: Six Essays for Managers. Toronto: York University Faculty of Administration Studies, Bureau of Research, 33-44.

Coase, Ronald (1970b), Discussion, in The Legal and Economic Aspects of Pollution. Chicago: The University of Chicago Center for Policy Study.

Coase, Ronald (1994), "Economics and Contiguous Disciplines", in Ronald Coase, Essays on Economics and Economists. Chicago: The University of Chicago Press, 34-46 [ed. orig.: 1977].

Elsner, Wolfram; Frigato, Pietro; Ramazzotti, Paolo (orgs.) (2006), Social Costs and Public Action in Modern Capitalism: Essays Inspired by Karl William Kapp's Theory of Social Costs. London: Routledge.

Fernandes, Abel Costa (2011), Economia pública - Eficiência económica e teoria das escolhas colectivas. Lisboa: Edições Sílabo [2. ${ }^{a}$ ed.].

Franzini, Maurizio (2006), "Social Costs, Social Rights and the Limits of Free Market Capitalism: A Re-reading of Kapp", in Wolfram Elsner; Pietro Frigato; Paolo Ramazzotti (orgs.) (2006), Social Costs and Public Action in Modern Capitalism: Essays inspired by Karl William Kapp's Theory of Social Costs. London: Routledge, 56-71.

Kapp, K. William (1963), "Social Costs and Social Benefits - A Contribution to Normative Economics", in Erwin Beckerath; Herbert Giersch (orgs.), Probleme der normativen Ökonomik und der wirtschaftspolitischen Beratung. Berlin: Duncker \& Humblot, 183-210.

Kapp, K. William (1965), "Social Economics and Social Welfare Minima", in T.K.N Unnithan et al. (orgs.), Towards a Sociology of Culture in India: Essays in Honor of Dr. D. P. Mukerji. New Delhi: Prentice Hall of India, 297-309. Versão eletrónica, consultada a 09.03.11, em http://www.kwilliam-kapp.de/documents/INDIAPDF.pdf Kapp, K. William (1969), "On the Nature and Significance of Social Costs", Kyklos, 22(2), 334-347.

Kapp, K. William (1970), "Environmental Disruption and Social Costs: A Challenge to Economics”, Kyklos, 23(4), 833-848. 
Kapp, K. William (1976), “The Open-System Character of the Economy and its Implications”, in Kurt Dopfer (org.), Economics in the Future. London: The Macmillan Press, 90-105.

Kapp, K. William (1977), "Environment and Technology: New Frontiers for the Social and Natural Sciences”, Journal of Economic Issues, 11(3), 527-539.

Kapp, K. William (1978), The Social Costs of Business Enterprise. Nottinghan: Spokesman [ed. orig.: 1963].

Medema, Steven (1994), Ronald H. Coase. London: Macmillan.

Medema, Steven (1996), "On Pangloss, Pigouvians and Pragmatism: Ronald Coase and Social Cost Analysis", Journal of the History of Economic Thought, 18 (Spring), 96-114.

Medema, Steven (2009), The Hesitant Hand: Taming Self-Interest in the History of Economic Ideas. Princeton: Princeton University Press.

Neves, Vítor (2012), “A análise dos custos sociais em Ronald Coase e K. William Kapp: duas perspetivas sobre a economia e a interdisciplinaridade”, in Celia Kerstenetzky; Vítor Neves (orgs.), Economia e interdisciplinaridade(s). Coimbra: Edições CES/ Almedina, 125-147.

Patel, Raj (2011), The Value of Nothing: How to Reshape Market Society and Redefine Democracy. London: Portobello Books Ltd.

Pearce, David (1978), "Introduction”, in David Pearce (org.), The Valuation of Social Cost. London: George Allen \& Unwin.

Pigou, Arthur C. (1932), The Economics of Welfare. London: Macmillan and Co. [ed. orig.: 1920]. Versão eletrónica, consultada a 15.01.12, em http://www.econlib.org/ library/NPDBooks/Pigou/pgEWCover.html

Robbins, Lionel (1984), An Essay on the Nature and Significance of Economic Science. London: MacMillan [3. ${ }^{\text {a }}$ ed.; ed. orig.: 1932].

Zerbe Jr., Richard (2001), Economic Efficiency in Law and Economics. Cheltenham: Edward Elgar. 